\title{
PENGUKURAN KUALITAS UX WEBSITE MENGGUNAKAN SUS
}

\author{
Feri Febria Laksana ${ }^{1}$, Suyoto $^{2}$ \\ ${ }^{1,2}$ Magister Teknik Informatika, Universitas Atma Jaya Yogyakarta \\ Yogyakarta, 55281, Indonesia \\ Iferi.febria@gmail.com, ${ }^{2}$ suyoto@uajy.ac.id
}

Abstrak-Penelitian ini menerapkan teori usability dan menggunakan metode pengukuran System Usability Scale (SUS). Uji validasi menggunakan pearson's product moment. Uji reliabilitas memakai alpha Cronbach. Berdasarkan hasil penelitian menunjukkan bahwa usability website 68.6 yang artinya pada peringkat $C$ atau OK Cukup Bagus. Loyalitas pengunjung website untuk melakukan kunjungan lagi (revisit) mendapatkan grand mean 3.5095. Nilai tersebut terletak pada rentang 3.40 - 4.20 yang menunjukkan bahwa loyalitas pengunjung untuk revisit terletak pada titik yang tinggi. Ada hubungan yang nyata namun tidak berarti antara variable kebergunaan (usability) dengan loyalitas pengunjung situs dibuktikan dengan Besaran nilai Sig. pada spearman correlation yang besarnya 0.041 . dan nilai Sig. tersebut lebih kecil dari nilai taraf kepercayaan yaitu 5\%nilai $r$ hitung yang positif yaitu 0.679 dan lebih besar dari r_tabel yaitu 1.966. Dapat disimpulkan apabila ariable usability ditingkatkan maka loyalitas akan ikut meningkat. Ditemukan hal yang menarik dalam penelitian yaitu pengunjung situs memanfaatkan situs lain dalam menelusuri berita informasi yang ada di dalam situs.

Keywords — Usability, sus, loyalitas pengunjung, website.

Abstract-This study uses usability theory and uses the System Usability Scale (SUS) measurement method. Validation test uses the moment of Pearson's product. Test reliability using Cronbach alpha. Based on the results of the study indicate that the usefulness of the website is 68.6 which means that on rank $C$ or OK it is quite good. The loyalty of website visitors to make another visit (revisit) gets an average value of 3,5095 . This value is located in the range $3.40-4.20$ which shows the visitor's loyalty to visit again placed at a high point. There is a real but not significant relationship between the sustainability of the variable (usability) and the loyalty of site visitors as evidenced by the magnitude of the Sig. in spearman the correlation is 0.041 . and Sig. This is smaller than the confidence level, which is $5 \%$, the positive value of $r_{-}$count is 0.679 and is greater than $r_{-}$tabel which is 1.966 . Can be abbreviated approved. Increased usefulness So loyalty will increase. It was found that interesting things in the study were site visitors who used other sites to access news information on the site.

Keywords - Usability, sus, visitor loyalty, website.

\section{PENDAHULUAN}

Menurut usability.gov usability atau dalam bahasa Indonesia yang memiliki arti kebergunaan yang merupakan ukuran kualitas suatu sistem atau aplikasi berupa kemudahan untuk dipelajari, digunakan dan mendorong pengguna untuk selalu memakai sistem tersebut dalam menyelesaikan suatu pekerjaan [1] [2]. Dalam membangun sebuah sistem, agar baik dan mudah digunakan oleh pengguna, salah satu komponen yang terpenting adalah kebergunaan yang baik [3]. Kebergunaan ini sangat berhubungan dengan user experience (UX). Peran UX dalam pembuatan aplikasi, bahkan dalam pembangunan sebuah situs, karena UX dapat menampilkan kemudahan yang dirasakan oleh pengguna dan efektif dalam berinteraksi dengan sistem tersebut. Banyak sistem yang telah dibuat tidak dilakukan tahap uji usability. Dikarenakan fokus penyelesaian masalah terdapat pada pengelolaan data dan berbagai masalah yang dihadapi, namun mengesampingkan faktor usability.

Pengukuran kesuksesan dari penerapan sebuah aplikasi dilaksanakan untuk menilai sejauh mana kemampuan pemakai dalam penggunaan aplikasi tersebut. Bahkan dari sisi emosi pengguna juga bisa dinilai menggunakan usability [4] . D. B. Setyohadi menyebutkan tentang dengan meningkatkan usability maka akan meningkatkan customer retention dari sebuah e-commerce pada penelitiannya [5]. Hasil penelitian ini akan dijelaskan dari penemuan, percobaan, pengamatan yang telah dilakukan penulis tentang tingkat kepuasan pengguna atas sistem yang diterapkan. Menurut Sahfitri, metode kuesioner sangat cocok digunakan karena berkaitan dengan efektifitas, efisiensi, dan kepuasan dalam pemakaian suatu aplikasi [6]. Instrumen kuesioner yang dipakai guna mengukur kebergunaan adalah System Usability Scale (SUS), dimana mampu memberikan ukuran persepsi secara subjektif dari pengguna tentang kegunaan suatu sistem, serta memungkinkan dikerjakan secara singkat selama sesi evaluasi, tanpa kehilangan komponen penting dari uji kebergunaan [7] yaitu efisiensi, efektifitas, kepuasan [8].

Dalam penelitian Leusmann, at. al, dapat segera dibenahi apabila hasil uji usability telah diperoleh [9] 
[10]. Selain itu, perolehan dari uji kebergunaan mampu menampilkan kecepatan dari suatu sistem (efektifitas dan efisiensi), dan loyalitas penggunanya [11] [12].

Hal itulah yang menyebabkan penulis melakukan Page | 139 penelitian ini guna melihat seberapa tingkat usability suatu sistem yang telah diterapkan pada lembaga pendidikan perguruan tinggi. Keinginan penulis ialah untuk seberapa tingkat usability di situs lembaga pendidikan perguruan tinggi dengan menggunakan metode pengukuran SUS serta hubungan antara kebergunaan dengan tingkat loyalitas pengunjung website.

\section{KERANGKA TEORI}

Fokus penelitian ini pada fenomena serta keterhubungannya dengan variabel lain yang bersifat kuantitatif dan sistematis [13]. Serta mengadopsi pendekatan single-case study, yang menerapkan pengujian usability instrumen yang digunakan menggunakan SUS. Peneliti menggunakan instrumen tersebut karena mampu memberikan ukuran persepsi secara subjektif dari pengguna tentang kegunaan suatu sistem [7]. Populasi dalam penelitian ini adalah pengunjung website Universitas PGRI Yogyakarta dengan alat bantu yaitu web statistik bernama similiarweb. Dengan total pengunjung pada bulan Januari 2019 berjumlah 130.000 [14]. Karena jumlah populasinya $\geq 100.000$. Maka peneliti menetapkan sampel dengan menggunakan tabel penentuan sample yang dikembangkan oleh Stephan Isaac dan Willian B. Michael, dengan tingkat error sebesar 5\% [15]. Maka diperoleh jumlah sampel yang akan diambil berjumlah 347 responden [16]

\section{A. Usability}

Pengukuran usability akan menggunakan SUS karena mudah digunakan dalam waktu singkat [7] tanpa mengurangi faktor penting dari uji usability yaitu efisiensi, efektifitas, kepuasan [8]. Cara mengukur usability adalah dengan perhitungan kelayakan yang diperoleh dari skor jawaban dibandingkan terhadap skor yang diharapkan, atau dapat di lihat pada rumus 1 [16].

$$
\underset{\text { Kelayakan (\%) }}{\text { Persentase }}=\frac{\text { Skor }_{\text {Observasi }}}{\text { Skor }_{\text {Diharapkan }}} \times 100 \%
$$

Maka berdasarkan rumus 1, diketahui:

Skor Observasi $_{\text {a }} 27450$ (diperoleh dari menjumlah seluruh skor usability yang diperoleh dari kuesioner)

Skor $_{\text {Diharapkan }}=40000$ (skor di harapkan 100 dari keseluruhan responden yaitu 400), maka:

$$
\begin{aligned}
& \begin{array}{c}
\text { Persentase } \\
\text { elayakan }(\%)
\end{array}=\frac{27450}{40000} \times 100 \% \\
& =68.6 \%
\end{aligned}
$$

Perolehan data, kemudian dikonversikan kemudian dibandingkan dengan melihat tabel kategori kelayakan pada tabel I.

TABEL I

KATEGORI KELAYAKAN

\begin{tabular}{|l|l|}
\hline Angka (\%) & \multicolumn{1}{|c|}{ Klasifikasi } \\
\hline$<21$ & Sangat tidak layak \\
\hline $21-40$ & Tidak layak \\
\hline $41-60$ & Cukup \\
\hline $61-80$ & Layak \\
\hline $81-100$ & Sangat layak \\
\hline
\end{tabular}

Bentuk instrumen SUS selengkapnya dapat dilihat pada tabel II.

\begin{tabular}{|c|c|}
\hline \multicolumn{2}{|r|}{ SUS } \\
\hline Kode & Pertanyaan \\
\hline Q1 & $\begin{array}{l}\text { Saya pikir bahwa saya akan lebih sering } \\
\text { menggunakan sistem ini }\end{array}$ \\
\hline Q2 & $\begin{array}{l}\text { Saya menemukan bahwa sistem ini, tidak } \\
\text { harus dibuat serumit ini }\end{array}$ \\
\hline Q3 & $\begin{array}{l}\text { Saya pikir sistem nya mudah dalam } \\
\text { penggunaan }\end{array}$ \\
\hline Q4 & $\begin{array}{l}\text { Saya pikir bahwa saya akan membutuhkan } \\
\text { bantuan dari orang teknis untuk dapat } \\
\text { menggunakan sistem informasi ini }\end{array}$ \\
\hline Q5 & $\begin{array}{l}\text { Saya menemukan beberapa variasi fungsi- } \\
\text { fungsi dari sistem ini yang telah terintegrasi } \\
\text { dengan baik }\end{array}$ \\
\hline Q6 & $\begin{array}{l}\text { Saya pikir ada begitu banyak } \\
\text { ketidakkonsistenan dalam sistem ini }\end{array}$ \\
\hline Q7 & $\begin{array}{l}\text { Saya membayangkan bahwa kebanyakan } \\
\text { orang akan belajar dengan sangat cepat untuk } \\
\text { menggunakan sistem ini. }\end{array}$ \\
\hline Q8 & $\begin{array}{l}\text { Saya menemukan sistem sangat rumit untuk } \\
\text { digunakan }\end{array}$ \\
\hline Q9 & $\begin{array}{l}\text { Saya merasa sangat percaya diri } \\
\text { menggunakan sistem }\end{array}$ \\
\hline Q10 & $\begin{array}{l}\text { Saya perlu belajar banyak hal sebelum saya } \\
\text { bisa melanjutkan dengan sistem ini }\end{array}$ \\
\hline
\end{tabular}

TABEL II

INSTRUMEN SUS

B. Loyalitas

Tujuan lain selain menguji tingkat usability website ialah untuk mengetahui loyalitas pengunjung website. Pada penelitian ini maksud dari loyalitas ialah keinginan dari pengunjung website untuk mengunjungi lagi situs dan terus mengakses www.upy.ac.id serta merekomendasikan-nya ke calon potensial pengguna lain baik sekedar untuk keperluan mencari sumber informasi, ataupun lainnya. Bentuk instrumen loyalitas selengkapnya pada tabel III. 
TABEL III

INSTRUMENT LOYALITAS

\begin{tabular}{|c|l|}
\hline \multicolumn{2}{|c|}{ LOYALITAS } \\
\hline Kode & \multicolumn{1}{c|}{ Pertanyaan } \\
\hline L1 & $\begin{array}{l}\text { Saya mengunjungi website lebih sering untuk } \\
\text { mencari kategori yang lain }\end{array}$ \\
\hline L2 & $\begin{array}{l}\text { Saya tidak hanya mengunjungi website tetapi } \\
\text { juga menelusuri informasi yang ada di dalam } \\
\text { website }\end{array}$ \\
\hline L3 & $\begin{array}{l}\text { Saya akan merekomendasi situs kepada orang } \\
\text { lain }\end{array}$ \\
\hline L4 & $\begin{array}{l}\text { Saya tidak menggunakan website lain untuk } \\
\text { penelusuran informasi seperti penelusuran } \\
\text { tentang pendidikan. }\end{array}$ \\
\hline
\end{tabular}

\section{Hipotesa}

Kesimpulan singkat yang merupakan jawaban yang bersifat sementara tentang masalah yang dihadapi dan dibuktikan benar tidak-nya oleh peneliti yang dirangkum menjadi hipotesa sebagai berikut:

1. Hipotesa alternatif $\left(H_{a}\right)$ : Terdapat hubungan antara kebergunaan dan loyalitas pengunjung situs UPY.

2. Hipotesa nol $\left(H_{0}\right)$ : Tidak ada hubungannya usability atas loyalitas pengunjung situs UPY.

\section{Skala Likert}

Dalam analisis kuantitatif responden diberikan lima pilihan jawaban seperti ditunjukkan pada tabel IV.

TABEL IV SKALA LIKERT

\begin{tabular}{|c|l|}
\hline Skor & Kriteria Jawaban \\
\hline 1 & Sangat Tidak Setuju (STS) \\
\hline 2 & Tidak Setuju (TS) \\
\hline 3 & Netral (N) \\
\hline 4 & Setuju (S) \\
\hline 5 & Sangat Setuju (SS) \\
\hline
\end{tabular}

\section{METODE PENELITIAN}

Pada penelitian ini mengadopsi pendekatan singlecase study. Yang dilakukan pada Perguruan Tinggi Swasta di Yogyakarta dengan menerapkan pengujian usability pada website instansi terkait. Instrumen yang digunakan ialah System Usability Scale (SUS), yang mampu memberikan ukuran persepsi secara subjektif dari pengguna tentang kegunaan suatu sistem. Dalam rangka memberikan cakupan yang lengkap dan pemahaman penuh dengan kedalaman penelitian ini, masing-masing aspek dari kriteria sampling untuk pengumpulan data dan analisis dijelaskan secara rinci. Lebih dari itu, reliabilitas dan validitas penelitian diperiksa. Untuk memberikan kejelasan yang lebih baik dan relevansi untuk pembacaan laporan penelitian ini, deskripsi kasus disajikan di awal bab hasil dan pembahasan.

\section{A. Uji Validasi}

Uji Validasi, merupakan metode pengujian untuk mengetahui valid tidaknya setiap pertanyaan dalam mendefinisikan variabel. Pengujian menggunakan correlate bivariate pearson (pearson's product moment) dan $r_{\text {tabel signifikan }}$ dengan $10 \%$ [17].

\section{B. Uji Reliabilitas}

Uji Reliabilitas, merupakan metode pengujian untuk mengetahui konsistensi alat ukur, dapat dipercaya dan konsisten jika pengujian tersebut dilaksanakan secara berulang-ulang atau tidak. Suatu instrumen dianggap reliabel apabila instrumen tersebut dapat dipercaya sebagai alat ukur data penelitian. Pada penelitian ini menggunakan ukuran cronbach's alpha [18].

\section{Analisis Deskriptif}

Sugiyono berpendapat guna keperluan analisa deskriptif maka data dikelompokkan menurut jenis responden dan variabel, lalu melakukan tabulasi data menurut variabel keseluruhan responden, kemudian disajikan. Dilakukan perhitungan guna menyelesaikan masalah yang telah dirumuskan, dan dilakukan perhitungan guna menguji hipotesa [16]. Sedangkan menurut Azwar dalam penelitiannya Arikunto, bukan untuk melakukan uji hipotesa merupakan pengertian dari analisa deskriptif [19]. Mean (x) pada penelitian ini berguna untuk memperoleh nilai rerata dari butirbutir pertanyaan.

$$
\text { Mean } X=\left(\sum_{i=1}^{n} X_{i}\right) / n
$$

Keterangan:

$\mathrm{n} \quad=$ Banyaknya responden

$x_{i}=$ Banyaknya skor dari sejumlah $\mathrm{i}$ instrumen

Mean $x=$ Nilai rata-rata dari setiap butir instrumen

Perhitungan rumus 2 pada masing-masing jawaban responden dicontohkan salah satu dari jawaban responden, sebagai berikut:

$$
\begin{aligned}
& \operatorname{Mean}(x)=\left(\sum_{i=4}^{n} x_{i}\right) / n \\
& \operatorname{Mean}(x)=(4+4+3+5+5) / 400 \\
& \operatorname{Mean}(x)=(21) / 400 \\
& \operatorname{Mean}(x)=0.0525
\end{aligned}
$$

Jadi total Mean $(x)$ pada jawaban responden bernilai 0.0525 . Dari nilai tersebut dilakukan perhitungan lagi menggunakan GrandMean $(x)$ yang disajikan pada rumus 3

$$
\text { GrandMean }(x)=\frac{\text { Total rata-Rata hitung }}{\text { Jumlah Pernyataan }}
$$

Perhitungan rumus 3 dari keseluruhan jawaban responden sebagai berikut:

$$
\begin{aligned}
& \operatorname{GrandMean}(x)=\frac{\text { Total rata }- \text { Rata hitung }}{\text { Jumlah Pernyataan }} \\
& \operatorname{GrandMean}(x)=\frac{17.55}{5} \\
& \operatorname{GrandMean}(x)=3.51
\end{aligned}
$$


Jadi total GrandMean ( $x$ ) pada penelitian ini bernilai 3.51. Dari hasil perhitungan GrandMean $(x)$ tersebut kemudian di cocokkan ke dalam rentang skala pada tabel V.

TABEL V

RENTANG SKALA

Page | 141

\begin{tabular}{|c|l|}
\hline Rentang Skala & Kriteria \\
\hline $4,20-5,00$ & Sangat Tinggi \\
\hline $3,40-4,20$ & Tinggi \\
\hline $2,60-3,40$ & Sedang \\
\hline $1,80-2,60$ & Rendah \\
\hline $1,00-1,80$ & Sangat Rendah \\
\hline
\end{tabular}

\section{Uji Korelasi}

Untuk uji korelasi menggunakan Spearman Rank Correlation. Menurut Sugiyono, untuk mengambil keputusan [16] yaitu jika hasil sig. kurang dari nilai probabilitas sebesar 0.05 kesimpulannya, adanya korelasi yang signifikan antar variabel yang dihubungkan. Namun jika hasil sig. lebih besar dari nilai probabilitas sebesar 0.05 maka, tidak adanya korelasi yang signifikan antar variabel yang dihubungkan. Kemudian diinterpretasikan ke correlation coefficient seperti pada tabel VI

TABEL VI

INTEPRETASI CORRELATION COEFFICIENT

\begin{tabular}{|c|l|}
\hline Interval Koefisien & Tingkat Hubungan \\
\hline 0.00 & Tidak ada hubungan \\
\hline $0.01-0.09$ & Hubungan kurang berarti \\
\hline $0.10-0.29$ & Hubungan lemah \\
\hline $0.30-0.49$ & Hubungan moderat \\
\hline $0.50-0.69$ & Hubungan kuat \\
\hline $0.70-0.89$ & Hubungan sangat kuat \\
\hline$>0.90$ & $\begin{array}{l}\text { Hubungan mendekati } \\
\text { sempurna }\end{array}$ \\
\hline
\end{tabular}

\section{E. Pengujian Hipotesa}

Uji hipotesa dilakukan menggunakan rumus pearson product moment. Berdasarkan penelitian pada Sujarweni, menyebutkan bahwa dengan menggunakan uji pearson product moment akan diketahui derajat keeratan hubungan 2 variabel yang memiliki skala interval atau rasio. Pengujian ini akan mengetahui nilai correlation coefficient. Jika nilai coefficient-nya -1 yang berarti korelasi yang negative sempurna, Namun jika nilai coefficient-nya 0 berarti tidak terdapat korelasi dan apabila coefficient-nya bernilai 1 memiliki arti adanya korelasi yang positif dan sempurna. Kemudian, dengan melihat rentang nilai antara -1, 0 dan 1. Dimana memiliki makna bahwa semakin erat jika mendekati nilai 1 atau -1 , sebaliknya akan bermakna semakin lemah jika semakin mendekati 0. Coefficient pearson product moment disajikan pada tabel VII.
TABEL VII

CORRELATION COEFFICIENT PEARSON PRODUCT MOMENT

\begin{tabular}{|c|l|}
\hline Interval Koefisien & Tingkat Hubungan \\
\hline $0.80-1,000$ & Sangat Kuat \\
\hline $0.60-0.799$ & Kuat \\
\hline $0.40-0.599$ & Sedang \\
\hline $0.20-0.399$ & Rendah \\
\hline $0.00-0.199$ & Sangat Rendah \\
\hline
\end{tabular}

Setelah $r_{\text {hitung }}$ diketahui, guna menguji hipotesa peneliti kemudian membandingkan $r_{\text {hitung }}$ dengan $r_{\text {tabel }}$, dengan syarat sebagai berikut:

1. $r_{\text {hitung }}>r_{\text {tabel }}$, maka $H_{a}$ diterima dan $H_{0}$ ditolak; dan

2. $r_{\text {hitung }}<r_{\text {tabel }}$, maka $H_{0}$ diterima dan $H_{a}$ ditolak.

\section{IV.HASIL DAN DISKUSI}

Penelitian ini menggunakan data yang dihasil dari 400 responden. Terdiri atas syarat responden berdasarkan tabel Issac dan Willian jumlah responden 347 dengan taraf kesalahan 5\%, kemudian penulis tambahkan 53 responden agar mempermudah penulis mengetahui nilai $r_{\text {tabel }}$ yakni 0.098. Pada pembahasan bagian ini, yaitu Uji Validasi, Uji Reliabilitas, Analisis hasil kuesioner, Uji kolerasi.

\section{A. Uji Validasi}

Pada instrumen usability, secara khusus, kehandalan ini berkaitan dengan replikasi hasil kuesioner. Maka SUS itu valid. Artinya, ia mengukur apa yang hendak diukur [7]. Pada instrumen Loyalitas, untuk instrumen loyalitas penulis melakukan pengujian kelayakan setiap pertanyaan dalam mendefinisikan variable. Pengujian menggunakan Pearson Product Moment dan $\mathrm{r}$ table signifikan dengan $5 \%$. Dapat dilihat dari $r_{\text {Hitung }}>r_{\text {Tabel }}$, maka statusnya dikatakan valid, dan sebaliknya jika $r_{\text {Hitung }}$ $<r_{\text {Tabel }}$. Hasil dari uji validitas loyalitas di sajikan pada tabel VIII.

TABEL VIII

UJI VALIDASI INSTRUMEN LOYALITAS

\begin{tabular}{|c|c|c|c|}
\hline Instrumen & $\boldsymbol{r}_{\text {Hitung }}$ & $\boldsymbol{r}_{\text {Tabel }}$ & Keterangan \\
\hline L1 & 0.429 & 0.098 & Valid \\
\hline L2 & 0.538 & 0.098 & Valid \\
\hline L3 & 0.397 & 0.098 & Valid \\
\hline L4 & 0.538 & 0.098 & Valid \\
\hline L5 & 0.564 & 0.098 & Valid \\
\hline
\end{tabular}

\section{B. Uji Reliabilitas}

Untuk mengukur reliabilitas, yang digunakan yaitu Alpha Cronbach. Pada instrumen usability, dalam penelitian ini peneliti menggunakan SUS karena, menurut Brooke metode ini "quick and dirty" dan dapat diandalkan [7]. SUS pada tahun 1986 diperkenalkan oleh John Brooke, menurut Brooke 
metode ini mampu mengukur bermacam-macam jenis layanan maupun produk, perangkat keras, perangkat lunak, perangkat seluler, web dan aplikasi. SUS dapat diandalkan. Pengguna merespons secara konsisten, dan SUS telah terbukti mendeteksi perbedaan pada ukuran sampel yang lebih kecil daripada kuesioner lainnya, SUS bukan diagnostik. Artinya, hal tersebut tidak memberi tahu apa yang membuat sistem dapat digunakan atau tidak [7].

Menurut Sujarweni, bahwa uji reliabilitas dilakukan agar instrumen loyalitas dapat dipercaya sebagai alat ukur data penelitian terhadap seluruh item pertanyaan [18]. Joko Widiyanto menjelaskan untuk mengambil keputusan dalam uji reliabilitas berdasarkan kriteria berikut [20]:

1. Jika Cronbach's Alpha $>r_{\text {tabel }}$ maka instrumen reliabel.

2. Jika Cronbach's Alpha $<r_{\text {tabel }}$ maka instrumen tidak reliabel.

3.

TABEL IX

\begin{tabular}{|} 
ReLIABILITAS INSTRUMEN LOYALITAS ' Alpha \\
\hline 0.220 & N of Items \\
\hline
\end{tabular}

Menurut hasil proses reliabilitas instrumen loyalitas menggunakan alat bantu SPSS yang disajikan pada tabel IXError! Reference source not found., maka untuk instrumen Loyalitas menghasilkan nilai Cronbach's Alpha sebesar 0.220. Sedangkan $r_{\text {Tabel }}$ untuk tingkat kesalahan sebesar 5\% adalah 0.098. Maka dapat disimpulkan bahwa instrumen loyalitas reliabel, karena $0.220>0.098$ ( $r_{\text {Hitung }}>$ $\left.r_{\text {Tabel }}\right)$.

\section{Analisis Hasil Kuesioner}

Pada pengukuran Usability, dilakukan perhitungan nilai SUS dengan pembobotan nilai akan berkisar dari 0 sampai 4. Menurut John Brooke pembobotan memiliki aturan sebagai berikut [7]:

1. Perhitungan pada nomor ganjil adalah posisi skala yang dikurangi dengan angka 1.

2. Perhitungan pada nomor genap adalah angka 5 dikurangi posisi skala.

Setelah itu menjumlah nilai serta melakukan perhitungan jumlah dengan mengalikan 2.5 agar diperoleh score total. Rentang nilai score SUS adalah 0-100. Setelah setiap responden diperoleh score SUS, score tersebut dihitung rata-rata score SUS nya. Dalam penelitian ini www.upy.ac.id memperoleh score SUS sebesar 68,6. Lalu kita proyeksikan ke dalam peringkat nilai score SUS, berdasarkan Gambar 1 membuktikan bahwa website www.upy.ac.id memperoleh score SUS sebesar 68,6 mendapat peringkat $\mathrm{C}$ yang artinya $\mathrm{OK}$. Serta mendekati angka 70 yang artinya OK cukup bagus.

Hasil intepretasi dari pengukuran usability website disajikan pada Gambar 1.

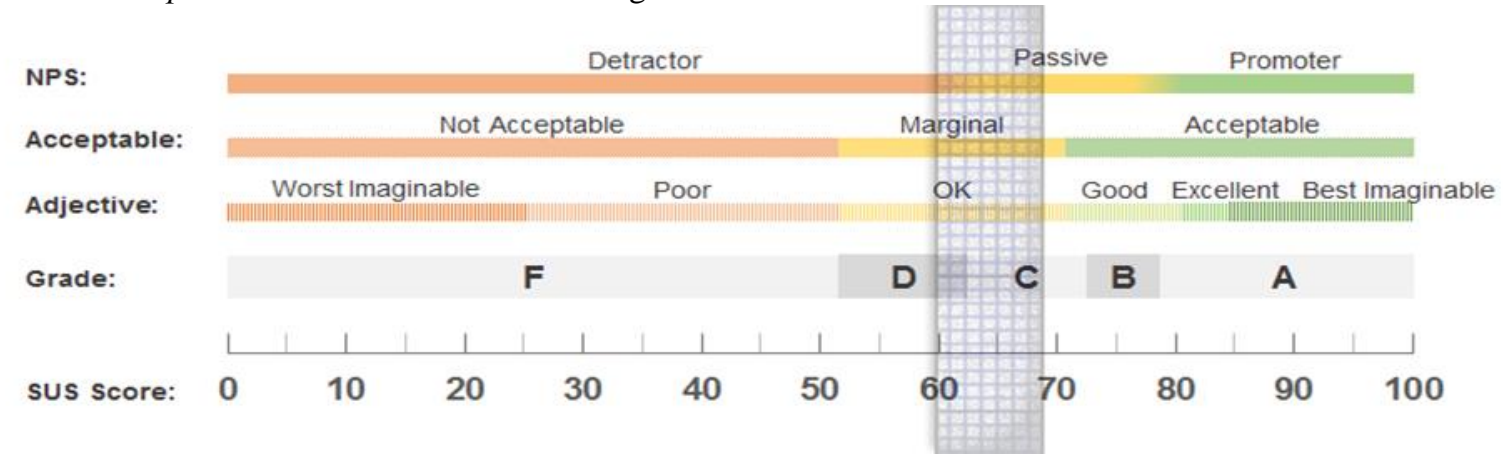

Gambar 1 Peringkat Score SUS Website UPY

\section{Uji Korelasi}

Pada uji korelasi menggunakan korelasi rank spearman digunakan pada penelitian statistik nonparametric (skala ordinal). Tujuan analisis korelasi secara umum ialah:

1. Mengetahui tingkat kekuatan (keeratan) hubungan antar variable.

2. Mengetahui arah (jenis) hubungan antar variable.

3. Mengetahui apakah hubungan tersebut signifikan atau tidak.

Tabel X adalah hasil dari proses pengujian korelasi spearman, menggunakan alat bantu SPSS:
TABEL X

HASIL KORELASI SPEARMAN SPSS CORRELATIONS

\begin{tabular}{|c|c|c|c|c|}
\hline & & & Usability & Loyalitas \\
\hline \multirow{6}{*}{ 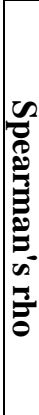 } & \multirow{3}{*}{ 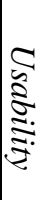 } & $\begin{array}{l}\text { Correlation } \\
\text { Coefficient }\end{array}$ & 1.000 & .72 \\
\hline & & Sig. (2-tailed) & . & .041 \\
\hline & & $\mathrm{N}$ & 400 & 400 \\
\hline & \multirow{3}{*}{ 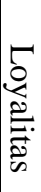 } & $\begin{array}{l}\text { Correlation } \\
\text { Coefficient }\end{array}$ & .72 & 1.000 \\
\hline & & Sig. (2-tailed) & .041 & - \\
\hline & & $\mathrm{N}$ & 400 & 400 \\
\hline
\end{tabular}


Pada TABEL Error! Reference source not found., agar mudah dimengerti, dapat interpretasikan sebagai berikut:

1. Tingkat kekuatan (keeratan) hubungan variabel kualitas kebergunaan dengan tingkat loyalitas pada TABEL nilai koefisien korelasi sebesar 0.72. Yang berarti tingkat kekuatan hubungan (korelasi) antara variabel kualitas kebergunaan dengan tingkat loyalitas adalah sebesar 0.72 atau memiliki hubungan yang tinggi (berdampak).

2. Variabel kualitas usability bernilai positif terhadap tingkat loyalitas dengan besaran nilai 0.72 , hal tersebut bersifat searah dan positif. Sama halnya dengan semakin ditingkatkannya kualitas usability maka tingkat loyalitas pun akan meningkat.

3. Dari hasil yang disajikan pada TABEL, nilai signifikansi sebesar 0.041. Nilai tersebut lebih kecil dari nilai taraf kepercayaan yaitu 0.05 , sehingga dapat disimpulkan adanya pengaruh terhadap tingkat loyalitas.

Maka penulis menyimpulkan, mengacu pada hasil korelasi spearman adalah terdapatnya hubungan yang signifikan antara variabel usability terhadap loyalitas pengunjung website, yang berarti apabila kualitas usability ditingkatkan akan meningkatkan loyalitas pengunjung website. Dengan semakin banyaknya pengunjung website maka besar kemungkinan pula tujuan dari pembuatan website tersebut akan tercapai.

\section{KESIMPULAN}

Berdasarkan analisis data penelitian bahwa tingkat usability website UPY atau www.upy.ac.id, memperoleh skor SUS sebesar 68.6 lalu interpretasi pada peringkat $\mathrm{C}$ yang berarti $\mathrm{OK}$ cukup bagus. Loyalitas pengguna untuk melakukan kunjungan lagi (revisit) pada website UPY, menghasilkan grand mean 3.5095. Nilai tersebut pada rentang $3.40-4.20$ yang menunjukkan bahwa loyalitas pengunjung website untuk melakukan kunjungan kembali (revisit) website UPY berada pada tingkat yang tinggi. Besaran nilai Sig. pada spearman correlation yang besarnya 0.041 . dan nilai Sig. tersebut lebih kecil dari nilai taraf kepercayaan yaitu 5\%, maka dapat disimpulkan ditemukannya pengaruh antara usability terhadap tingkat loyalitas atau apabila variabel usability ditingkatkan maka loyalitas akan ikut meningkat. Ditemukan hal yang menarik dalam penelitian yaitu pengunjung situs memanfaatkan situs lain dalam menelusuri informasi yang ada di dalam situs.

Untuk penelitian selanjutnya, menambahkan objek agar dijadikan sebagai perbandingan namun $\mathrm{di}$ usahakan objek tersebut memiliki derajat dan perilaku yang sama. Untuk penelitian berikutnya yang mengenai mahasiswa, waktu penelitian yang tepat harap menyesuaikan waktu yang dimiliki oleh subjek penelitian agar responden dapat mengisi kuesioner dengan sebaik-baiknya.

Menurut hasil penelitian, peneliti merekomendasikan dengan meningkatkan usability peneliti meyakini akan lebih memaksimalkan fungsi dari website yang arti nya akan menambah jumlah pengunjung website dan akan berdampak pada proses marketing dibisnis pendidikan.

\section{REFERENSI}

[1] A. Bangor, P. T. Kortum and J. T. Miller, An Empirical Evaluation of the System Usability Scale, Publishing models and article dates explained, pp. 574-594.

[2] usability.gov, $2018 . \quad$ [Online]. Available: https://www.usability.gov/what-and-why/usabilityevaluation.html.

[3] J. Nielsen, "Usability 101: Introduction to Usability," January $2012 . \quad$ [Online]. Available: https://www.nngroup.com/articles/usability-101-introductionto-usability/. [Accessed 2017].

[4] D. B. Setyohadi, S. Kusrohmaniah, E. Christian, L. T. Dewi and B. P. Sukci, "M-Learning Interface Design Based on Emotional Aspect Analysis," 2017.

[5] D. H. Yohandy and D. B. Setyohadi, "Usability Evaluation Using Multi-Method for Improvement Interaction in MCommerce," in MATEC Web of Conferences, 2018.

[6] V. Sahfitri and M. Ulfa, "Evaluasi Usability Sistem ELearning sebagai Aplikasi Pendukung Proses Pembelajaran di Perguruan Tinggi Menggunakan USE Questionnaire," Jurnal Ilmiah MATRIK, vol. 17 No. 1, pp. 53-66, 2015.

[7] J. Brooke, "SUS: A Retrospective," Journal Of Usability Studies, vol. 8, no. 2, pp. pp. 29-40, 2013.

[8] ISO Organisation, "Ergonomics of human-system interaction - Part 11: Usability: Definitions and concepts," 2018. [Online]. Available: https://www.iso.org/obp/ui/\#iso:std:iso:9241:-11:ed-2:v1:en. [Accessed 2017].

[9] S. B. Leusmann, C. Samsel, M. Wiederhold, K. H. Krempels, E. M. Jakobs and M. Ziefle, "sability Evaluation of Mobile Passenger Information Systems," in Proceedings of the 16th International Conference on Human-Computer Interaction, 2014.

[10] . T. H. Kim and S. H. Jin, "Development of auditory design guidelines for improving learning on mobile phones," Computers \& Education, vol. 91, no. C, pp. 60-72, Desember 2015.

[11] J. Sang, T. Mei, Y.-. Qing Xu and C. Zhao, "Interaction Design for Mobile Visual Search," IEEE Transactions on Multimedia, vol. 15, no. 7, pp. 1665 - 1676, November 2013.

[12] R. Blanco-Gonzalo, R. Sanchez-Reillo, O. Miguel-Hurtado and E. Bella-Pulgarin, "Automatic usability and stress analysis in mobile biometrics," Image and Vision Computing, vol. 32, no. 12, pp. 1173-1180, Desember 2014.

[13] J. W. Creswell, Research Design: Qualitative, Quantitative, and Mixed Methods Approaches, 4th ed., SAGE, 2014.

[14] SimiliarWeb, "Website Trafic Statistik dan Market Intelligence," $2018 . \quad$ [Online]. Available: https://www.similarweb.com/website/uty.ac.id. [Accessed 2019].

[15] S. Isaac and W. B. Michael, Handbook in Research and Evaluation, San Diego: Robert R. Knapp, 1971, p. vi + 186.

[16] Sugiyono, Metode Penelitian Kuantitatif, Kualitatif, dan R\&D, 28 ed., Bandung: Alfabeta, 2018.

[17] Laerd Statistic, 2019. [Online]. Available: https://statistics.laerd.com/statistical-guides/pearsoncorrelation-coefficient-statistical-guide.php.

[18] V. W. Sujarweni, SPSS untuk Penelitian, Yogyakarta: Pustaka Baru Press, 2014 
[19] S. Arikunto, Prosedur Penelitian: Suatu Pendekatan Praktik, Jakarta: PT Rineka Cipta Jakarta, 2010.

[20] J. Widiyanto, "SPSS For Windows untuk analisis data statistik dan penelitian," Surakarta: BP-FKIP UMS, 2010.

Page | 144 